\title{
Foliar Nutrient Management on Potato Grown under Zero Tillage and Mulching in Coastal Saline Soil of West Bengal, India ${ }^{+}$
}

\author{
Koushik Brahmachari 1,*, Sukamal Sarkar ${ }^{1}$, Deepak Sahoo 1, Indranil Samui 1, \\ Manoj Kumar Nanda ${ }^{2}$, Argha Ghosh ${ }^{2}$ and Mohammed Mainuddin ${ }^{3}$ \\ 1 Bidhan Chandra Krishi Viswavidyalaya, Department of Agronomy, Mohanpur 741252, India; \\ sukamalsarkarc@yahoo.com (S.S.); deepak999955@gmail.com (D.S.); indranilsamui@gmail.com (I.S.) \\ 2 Bidhan Chandra Krishi Viswavidyalaya, Department of Agricultural Meteorology and Physics, \\ Mohanpur 741252, India; mknandabckv@rediffmail.com (MK.N.); ghoshargha4@gmail.com (A.G.) \\ 3 CSIRO Land and Water, Canberra 2601, Australia; mohammed.mainuddin@csiro.au \\ * Correspondence: brahmacharis@gmail.com \\ † Presented at the third International Tropical Agriculture Conference (TROPAG 2019), Brisbane, Australia, \\ 11-13 November 2019.
}

Published: 26 December 2019

\begin{abstract}
The Costal Saline Zone (CSZ) of West Bengal, India is dominated by rice-fallow-fallow system cropping system. Only $4 \%$ of the cultivated area of the coastal zone can be irrigated with available sweet water. To cope up with the present situation is introduction of new high value crops to catch the fallow winter period emphasizing on water saving technologies. In this way monocropped saline soils of coastal region can be converted into multiple cropping through the adoption of zero tillage potato technology. Soils of the CSZ show multi-nutritional deficiencies and these deficiencies adversely affect the crop. To address this issue, field experiment was conducted in winter season of 2016-2018 in CSZ of West Bengal, India with the focal objectives of studying the feasibility of potato under zero-tilled-mulched condition in CSZ of West Bengal; assessing the effect of foliar nutrient management practices on growth, yield, quality and economics of potato. The foliar nutritional supplementation with $2 \%$ Urea at $30 \& 50$ days after planting (DAP) of potato along with $0.1 \%$ Boron at 30 DAP not only increased tuber number and yield but also quality parameters of potato tuber such as TSS, tuber hardness, vitamin C etc. were significantly increased. It may thus be concluded that $2 \%$ Urea at $30 \& 50$ at DAP of potato along with $0.1 \%$ Boron at $30 \mathrm{DAP}$ as foliar application is the best foliar nutrient management option for potato grown under zero tillage and mulching in coastal saline soils of West Bengal, India.
\end{abstract}

Keywords: potato; micronutrients; foliar application; coastal soil; zero tillage

Funding: Australian Centre for International Agricultural Research (ACIAR).

Conflicts of Interest: The authors declare no conflict of interest.

(C) 2019 by the authors. Licensee MDPI, Basel, Switzerland. This article is an open access article distributed under the terms and conditions of the Creative Commons Attribution (CC BY) license (http://creativecommons.org/licenses/by/4.0/). 